\title{
AIR EMBOLISM DURING PNEUMOPERITONEUM TREATMENT
}

\author{
BY \\ DAVID BURMAN \\ From Tan Tock Seng Hospital, Singapore
}

(RECEIVED FOR PUBLICATION OCTOBER 28, 1955)

Air embolism is the most dramatic complication of artificial pneumoperitoneum. Little is known, however, of its incidence, its mortality rate or the relative risks of induction and refill. This paper discusses these problems and the methods of prevention and treatment most likely to be successful.

The material consists of six newly reported cases and 47 cases collected from the literature. The six original cases occurred during the year ending October 31, 1953, in the practice of Tan Tock Seng Hospital, Singapore. During this time 53,534 refills and 926 inductions were given in the course of pneumoperitoneum treatment. Of the refills $89.4 \%$ and of the inductions $75.5 \%$ were performed on out-patients. The 47 cases from the literature are analysed in Table I, from which the cases of Aslett and Jarman (1945) have deliberately been omitted, as it is doubtful if they are cases of air embolism (Lancet, 1945). The case described by Burgos (1946) has also been omitted, as I have been unable to obtain a copy of this paper, and I have no doubt several other cases have been omitted inadvertently.

\section{CASE REPORTS}

CASE 1.-A Chinese man aged 29 had a pneumoperitoneum induced on November 3, 1952, for cavitating tuberculosis of the right upper lobe with bronchogenic spread to both lungs. On December 3, 1952, for his fifth refill, a Morland's needle was inserted into the lateral border of the left rectus sheath above the umbilicus. The initial pressure was recorded as $15 \mathrm{~cm}$. of water whereas on previous occasions it had been $10 \mathrm{~cm}$. Air, $600 \mathrm{ml}$., was given by a Maxwell apparatus and, as the pressure then recorded was $18 \mathrm{~cm}$. of water, the refill was stopped. On rising from the couch, he immediately fell to the floor unconscious and had a tonic fit. When placed on the couch again the jaws were tightly clenched, the airway was obstructed, and he became cyanosed although the pulse was full and of normal rhythm. When the jaw relaxed, the cyanosis rapidly disappeared and within 10 minutes of the onset he had regained consciousness although he was still disorien- tated. An hour later he was symptom free and was discharged from the ward the following day to continue the pneumoperitoneum without further incident.

CASE 2.-A 29-year-old Chinese woman had a pneumoperitoneum induced on May 12, 1952, for tuberculous infiltration of both apices. On June 3, 1953, a Morland needle was inserted into the lateral border of the left rectus sheath 1 in. $(2.5 \mathrm{~cm}$.) above the umbilicus and $1,500 \mathrm{ml}$. of air was given with a Maxwell apparatus. During this time the patient complained of abdominal discomfort. She got up from the couch and immediately collapsed unconscious on the floor. She was replaced on the couch, which had its foot raised 24 in. $(60 \mathrm{~cm}$.), and was given oxygen. She was pale, cold, pulseless, completely apnoeic, and in a tonic convulsion with extension of the legs, flexion of the arms, and deviation of the eyes upwards and to the left. After about 45 seconds, gasping respirations and a feeble, irregular pulse began. Auscultation over the lower sternum revealed a "crunching" systolic sound which lasted about 10 minutes and was accompanied by moderate cyanosis. Fifteen minutes later she regained consciousness but was restless and confused. There were no neurological signs, but she had been incontinent, had bitten her tongue, and had a haematoma above the left eye. After one and a half hours she appeared quite well except for a headache which had disappeared by the following morning. The pneumoperitoneum has since been continued without any difficulty.

CASE 3.-A Chinese man aged 26 years had a pneumoperitoneum induced on April 25, 1952, for bilateral apical cavitation of tuberculous origin. On June 8, 1953, a Morland needle was inserted through the lateral border of the rectus sheath $\frac{3}{4}$ in. $(2 \mathrm{~cm}$.) above the umbilicus and to its left. With a Maxwell apparatus $400 \mathrm{ml}$. of air had been given when the patient complained of discomfort in the lower chest and epigastrium, and the pressure, when the flow of gas was stopped, returned very slowly to its initial level of $+6 \mathrm{~cm}$. of water. The position of the needle was adjusted and a further $1,200 \mathrm{ml}$. was given without difficulty. Directly the needle was withdrawn, he complained of difficulty in breathing and tingling of the fingers. He lost consciousness, had a tonic fit, became cyanosed with stertorous, rapid respiration and developed a weak, irregular, rapid pulse. A typical "mill-wheel" murmur could be heard over the 
base of the heart. The foot of the bed was immediately raised about 18 in. (45 cm.) and oxygen was administered through a B.L.B. mask. Within five minutes he had regained consciousness, had normal respirations and colour although his pulse was still rapid. He was admitted to the ward, but three hours later discharged himself against advice. He has been well since and continues to have his refills every fortnight.

Case 4.-A Chinese woman, aged 44, with tuberculous cavitation of the right upper lobe, was considered suitable for a pneumoperitoneum and later a right phrenic crush. On June 20,1953, induction was attempted by inserting a Morland needle into the lateral border of the left rectus sheath $\frac{1}{2}$ in. $(1.3 \mathrm{~cm}$.) above the umbilicus.

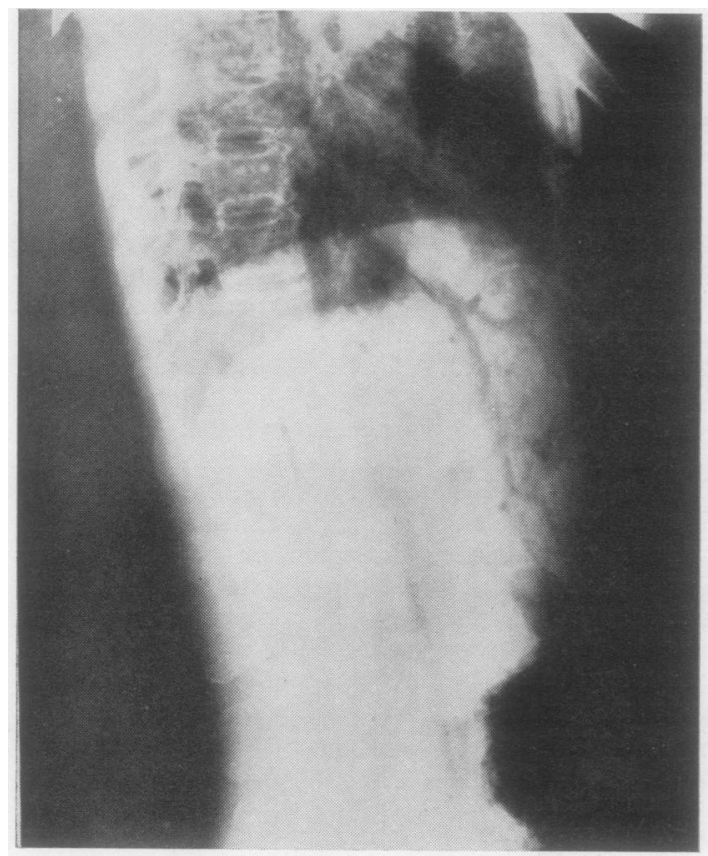

FIG. 1.-Post-mortem radiograph of the abdomen (lateral view) of Case 4 showing air in the hepatic veins, inferior vena cava, and common iliac veins.

Air, $200 \mathrm{ml}$., was given with a Maxwell pneumothorax apparatus, and on all occasions when the flow of air was stopped, the pressure immediately fell to $5 \mathrm{~cm}$. of water. A further $200 \mathrm{ml}$. was given and the pressure was then recorded as $15 \mathrm{~cm}$. of water. At no time did the patient complain of discomfort, but as the needle was withdrawn she took a few deep rapid breaths and started a tonic fit with extension of the legs and spine and flexion of the arms. She was unconscious, with dilated pupils, inaudible heart sounds and cyanosis. Apart from two short gasps, she showed no other signs of life despite the raising of the foot of the couch $18 \mathrm{in} .(45 \mathrm{~cm}$.), the administration of oxygen, and injections of $3 \mathrm{ml}$. of nikethamide intravenously, and of $0.5 \mathrm{ml}$. of $1: 1,000$ adrenaline into the heart.
At necropsy (Dr. L. S. da Silva) it was found that the left lobe of the liver was enlarged to the level of the umbilicus and that the needle had been inserted into the liver substance $\frac{1}{2}$ in. $(1.3 \mathrm{~cm}$.) from its lower edge. The under surface of the liver showed a subcapsular haemorrhage, but the capsule was intact. Air was found in the vessels of the liver, the hepatic veins, the inferior vena cava, the common iliac veins, the right atrium and ventricle and the pulmonary artery. Air was also found in the pial vessels of the vertex and the circle of Willis and its branches, although the foramen ovale of the auricular septum was not patent.

The radiographs (Figs. 1, 2, and 3) were taken five hours after death and show (Figs. 1 and 2) the enlarged

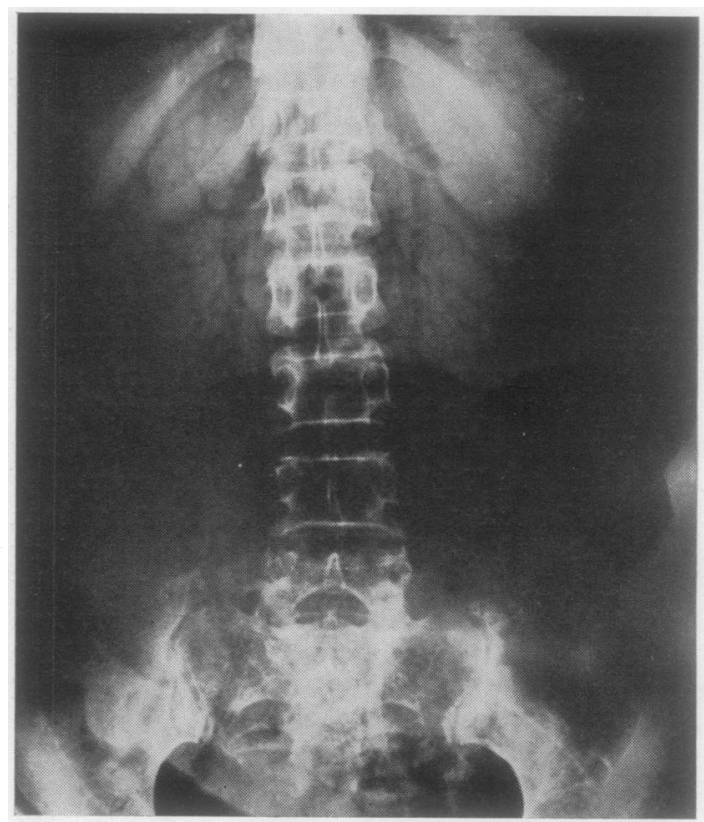

FIG. 2.-Antero-posterior view of the abdomen of Case 4 showing air in the hepatic system of veins.

left lobe of the liver and the venous system of both lobes outlined by air. Air is also seen in the inferior vena cava and both common iliac arteries, but there is none in the peritoneal cavity. In the chest (Fig. 3) the right cardiac border is prominent and encloses a patchy translucent area which was seen at necropsy to be a mixture of blood and air in the right atrium and ventricle. Air can also be seen in the veins of the neck and the left axillary vein. These radiographs are very similar to those published by Taylor (1952).

CASE 5.-A Chinese woman, aged 26 years, had a pneumoperitoneum induced on March 12, 1951, and the left phrenic nerve crushed one month later for tuberculous cavitation of the left lung. On July 30, 1953, 
while she was known to be five months pregnant, a Saugman needle was inserted into the lateral border of the left rectus sheath at the level of the umbilicus, and air was injected with a modified Lillingston-Pearson pneumothorax apparatus. During this time she complained of slight abdominal discomfort, and, when $500 \mathrm{ml}$. had been given, she became unconscious and started a tonic fit with extension of the legs and spine and flexion of the arms. She became cyanosed, with a

away. On arrival at the ward, she was again cyanosed with a weak pulse and general muscle spasm. She was given oxygen and her bed placed on 24 in. $(60 \mathrm{~cm}$.) blocks. She recovered in a few minutes.

Two hours later the patient appeared well except for a pulse rate of 136 per minute and a temperature of $99.2^{\circ} \mathrm{F}$.; there were no neurological signs, no abnormal heart sounds, and the blood pressure was $110 / 80 \mathrm{~mm}$. of mercury. The uterus was no longer tense, but a succussion splash could be heard over the lower abdomen. The foot of the bed was lowered on to 15 in. $(37 \mathrm{~cm}$.) blocks and the patient again became cyanosed, vomited, and was incontinent. The bed was replaced on the 24 in. $(60 \mathrm{~cm}$.) blocks, oxygen was given and the patient rapidly recovered. After a further two hours the bed was lowered on to 15 in. (37 cm.) blocks and after another two hours it was placed on 6 in. $(15 \mathrm{~cm}$.) blocks; both movements were without any effect on the patient. The following morning the patient was discharged from the ward, but her pneumoperitoneum was abandoned.

A radiograph, taken to elucidate the cause of the succussion splash, showed a moderate peritoneal effusion.

CASE 6.-A 52-year-old male Malay had a pneumoperitoneum induced in December, 1949, for tuberculous cavitation of the left upper lobe and infiltration without cavitation on the right. On August 25, 1953, a Morland needle was inserted into the lateral border of the left rectus sheath $\frac{1}{2}$ in. $(1.3 \mathrm{~cm}$.) above the umbilicus. An initial pressure of $+6 \mathrm{~cm}$. of water was recorded, but after $300 \mathrm{ml}$. had been given with a Maxwell apparatus the patient suddenly started to breathe rapidly, became cyanosed and had generalized clonic movements with loss of con-

feeble, irregular pulse, and was incontinent of urine. The fundus of the uterus was found to be at the level of the umbilicus and noted to be unusually tense. The foot of the couch was raised on $24 \mathrm{in}$. $(60 \mathrm{~cm}$.) blocks, oxygen was given by B.L.B. mask, and $3 \mathrm{ml}$. of nikethamide injected intramuscularly. Within two or three minutes she regained consciousness, the fit stopped and the cyanosis disappeared, but she still complained of abdominal pain. Ten minutes later she was placed flat on a stretcher and carried to the ward about 30 yards sciousness. His pulse was rapid and weak and a typical "mill-wheel" murmur could be heard over the praecordium. He was immediately given oxygen and the foot of his couch was raised on to $24 \mathrm{in}$. $(60 \mathrm{~cm}$.) blocks. Within 15 minutes he regained consciousness, and the murmur and cyanosis disappeared. After 30 minutes he appeared normal, and the oxygen was stopped. Two hours after the fit the foot of the bed was lowered on to 9 in. $(23 \mathrm{~cm}$.) blocks, and after a further two hours was placed horizontal. 
A radiograph showed multiple adhesions attached to the under surface of the left diaphragm. His refills have since been continued without incident, the needle being inserted into the lateral border of the right rectus sheath.

\section{ESTIMATED INCIDENCE AND MORTALITY}

In Table I published cases of air embolism associated with pneumoperitoneum treatment are summarized. Thirteen are stated to have occurred during induction and 29 during a refill of pneumo- peritoneum. Five authors either state their experience of the incidence of air embolism during induction or give figures from which it can easily be deduced if it is assumed that each patient has only one induction. Aggregation of these experiences shows that five air emboli occurred in 2,185 inductions or an incidence of 1 in 437 . Seven authors in Table I state their experiences of the incidence of air embolism complicating refills, and, if it is assumed that the majority of Hollander's (1951)

TABLE I

SUMMARY OF PUBLISHED CASES OF AIR EMBOLISM COMPLICATING ARTIFICIAL PNEUMOPERITONEUM AND OF SIX NEW CASES

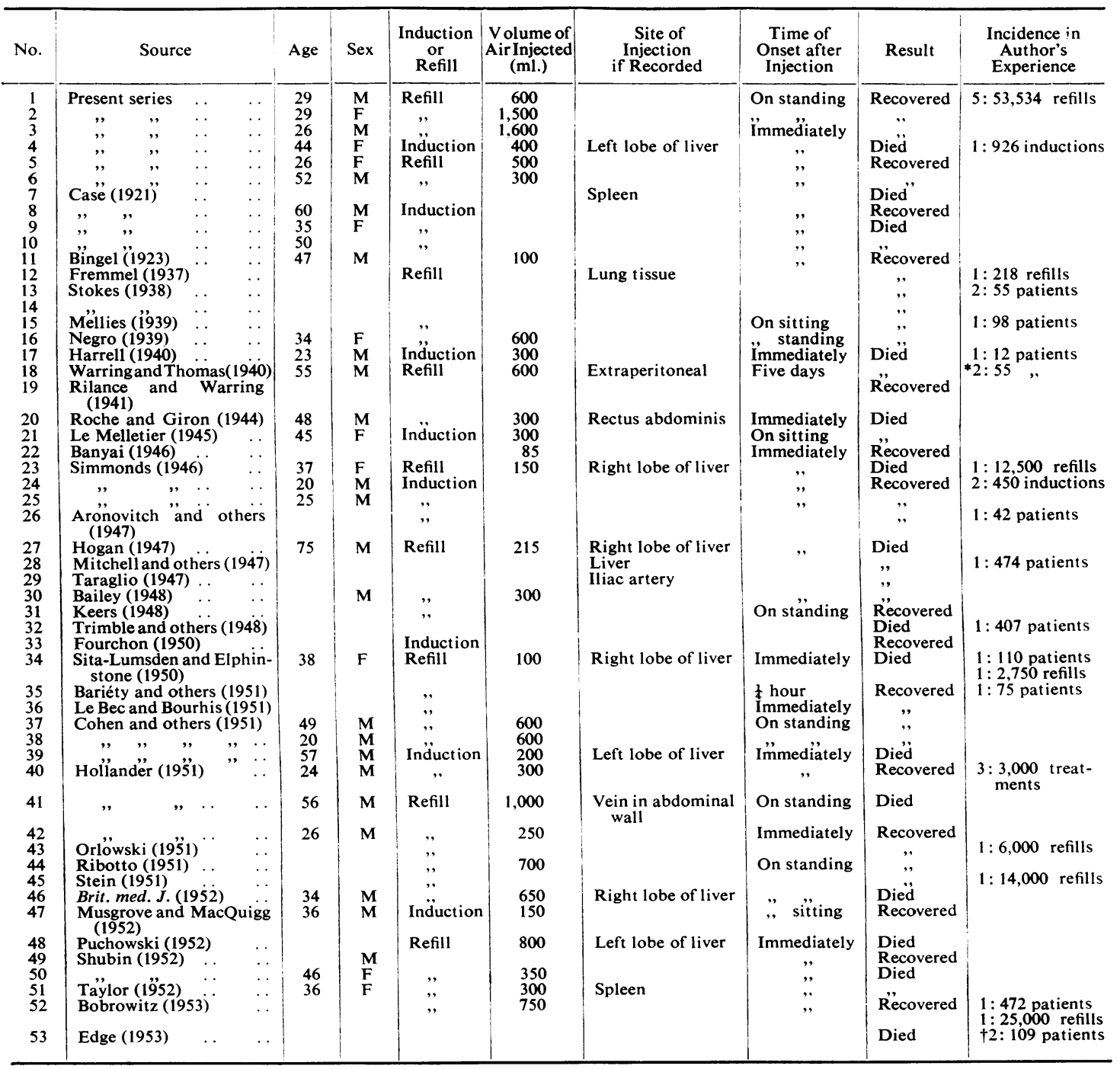

* Includes Case No. 19. † Includes Case No. 31. 
treatments were refills, then 13 air emboli occurred during 117,002 refills or an incidence of 1 in 9,000 . These figures must be maximal incidences, for many of the authors have published their cases in order to describe an air embolism occurring early in their experience, and the experience of those with no experience of air embolism is not taken into consideration. This would particularly appear to be the case with air embolism complicating induction where individual figures vary from 1 in 12 to 1 in 926. Assuming that the latter figure is nearer the true incidence the risk of air embolism during induction is about 10 times that of a refill. However, each patient is likely to continue his pneumoperitoneum for about three years, during which time he will receive approximately 100 refills. Even if the incidence estimated above is accepted as being somewhat too high, then approximately $1 \%$ of patients will have an air embolism during a course of pneumoperitoneum therapy. Eleven authorities in Table I state the number of patients among whom their cases of air embolism occurred. If these are aggregated, 17 air emboli occurred among 2,359 patients or an incidence of 1 in 136. This agrees fairly closely with $1 \%$ calculated above, particularly as 1 in 136 is probably too low because in some authors' series the duration of treatment was very short (e.g., Mitchell, Hiatt, McCain, Easom, and Thomas, 1947). The incidence of air embolism complicating pneumothorax refills has been estimated as between 1 in 2,000 and 1 in 3,000 (Durant, 1935; Hogan, 1947). This figure is considerably higher than the maximal incidence of air embolism complicating pneumoperitoneum calculated above.

Of the 53 cases included in Table I, 22 or $41.5 \%$ of the total, 11 or $38 \%$ of the 29 refills, and six or $46 \%$ of the 13 inductions were fatal. There is thus no significant difference between the mortality rate of air embolism complicating induction or refill of pneumoperitoneum, but the rate appears to be higher than the 33\% reported by Hogan (1947) and the $22 \%$ reported by Hamilton and Rothstein (1935) for the mortality rate of air embolism complicating pneumothorax. This is surprising, for it would be expected that the mortality occurring during pneumothorax therapy would be higher because a proportion of air emboli in pneumothorax treatment are of the arterial type, which experimentally requires only $0.5 \mathrm{ml}$. of air per $\mathrm{lb}$. of body weight to produce death regularly (Moore and Braselton, 1940), whereas all in pneumoperitoneum therapy are of the venous type and require much larger volumes of air to be fatal (e.g., $7 \mathrm{ml}$. per lb. of body weight as reported by Wolffe and Robertson, 1935). The figure $41.5 \%$ is almost certainly unduly high, because some of the cases are reported by pathologists, and isolated cases which recover always have less chance of being reported than those which are fatal.

\section{Prevention of Air Embolism}

Before discussing the treatment of air embolism in pneumoperitoneum therapy it is advisable to discuss how these accidents can be avoided. The aetiological factor which most authors have emphasized is the inexperience of the operator. In only one of the six cases in the present series was the operator's experience of pneumoperitoneum therapy greater than one year.

The apparatus used also seems to be an important factor in the production of the present series of air emboli, for it will be noted that in five cases a Maxwell pneumothorax apparatus and a Morland needle were used whereas this apparatus is used in only about $50 \%$ of the refills performed at Tan Tock Seng Hospital. In the other cases a seesaw type of Lillingston-Pearson apparatus is used with a Saugman needle. The probable reason for this is the ease with which a high pressure can be applied with the Maxwell apparatus, although the design of the needle is also important. Cafiero and Mastropaolo (1952) mention the low incidence of air embolism associated with the use of a needle with a lateral aperture, but it would seem possible that only half of the aperture might be in the peritoneal cavity, while the other half was in the tissues. In this case air could be injected into the tissues, yet the pressure would fall rapidly when the flow of gas was stopped. This is almost impossible if the needle has a terminal aperture and particularly if it has a short bevel. A further advantage of a Saugman needle is that a stylet may be passed through it or a syringe may be attached and aspiration attempted before injecting air; this, Le Melletier (1945) considers, is the most important method of preventing the complications of pneumoperitoneum therapy.

The site of insertion of the needle appears to influence the incidence of air embolism. Of the cases summarized in Table I, five were due to puncture of the right lobe of the liver; and, on the left side, an abnormally large left lobe of the liver has been punctured on three occasions (Cases 4, 39, and 48), and puncture of the spleen has produced air embolism in two cases (Cases 7 and 51) and haemorrhage in several others (Trimble, Eaton, Crenshaw, and Gourley, 1948; Burman, 1954). If, however, the needle is inserted too low in the abdomen there is the risk of puncturing a pregnant uterus; this accident appears a possibility in Case 5 , and cer- 
tainly occurred in the case described by Weiss (1951), who inserted the needle in the midline below the umbilicus. Careful palpation and the routine use of the lateral border of the left rectus sheath at the level of the umbilicus or even lower (Cafiero and Mastropaolo, 1952) are probably the best ways of avoiding the viscera.

While the air is being injected, its flow should be stopped periodically to ensure that the manometer records an immediate fall in pressure. This sign is more important in determining whether the needle is in the peritoneum than fluctuations with respiration which are frequently absent. It is important to read the manometer frequently in the early stages of a refill, for an air embolism has occurred after the injection of only $85 \mathrm{ml}$. of air (Banyai, 1946) and a fatal case after $100 \mathrm{ml}$. (SitaLumsden and Elphinstone, 1950).

If it is suspected that the air has been inserted into the tissues, then the needle must be immediately withdrawn and the patient remain lying down. The reason for this is easily seen from Table I, for, of 39 cases in which the time of onset is stated, three occurred on sitting up and 10 on standing or walking a few paces. One third of the cases thus occur on moving from the couch, and some of these might have been prevented had the patient remained horizontal. The patient, however, would have to remain lying down for several hours to allow the intravascular nitrogen to be absorbed. Suspicion that the air may be entering the tissues must be entertained if the patient complains of abdominal discomfort (as happened in Cases 2, 3, and 5 described above), if the pressure does not fall when the flow of gas is stopped, or if there is blood on the point of the needle. To these indications, Gabus (1952) adds an unexplained spasm of coughing, localized swelling, or restlessness.

\section{Treatment of Air Embolism}

To be successful, the treatment of air embolism must be started directly the diagnosis is made. The essential treatment consists of four steps: change in posture, the administration of oxygen, aspiration of the right ventricle, and artificial respiration.

The patient must first be placed in a steep Trendelenburg position; Bohorfoush (1943) emphasizes that the patient must be almost vertical. In the case described by Le Bec and Bourhis (1951), the patient was held vertically for a quarter of an hour by four men. Secondly, the patient must be turned on to his left side, for this has been shown experimentally in dogs to be a most successful manœuvre
(Oppenheimer, Durant, and Lynch, 1953), and Hamby and Terry (1952) noticed immediate improvement when their patient was turned on to his left side. The left lateral and Trendelenburg positions were successfully used by Musgrove and MacQuigg (1952). This position causes the air, which collects in the right ventricle, to move away from the opening of the pulmonary artery; this allows a limited circulation to proceed even though there is still air in the right ventricle. If, as Forbes (1944) has suggested, death is due to blockage of the pulmonary artery itself or the smaller arterioles of the lungs, then these manœuvres will probably not be successful. Elevation of the feet may also prevent air in the abdominal veins reaching the right ventricle via the inferior vena cava or the cerebral sinuses via the vertebral plexus of veins. At Tan Tock Seng Hospital 24 in. $(60 \mathrm{~cm}$.) blocks were designed to raise the foot of the bed. If the blocks were any higher, it was found that the patient would slide off the couch when turned into the left lateral position. The time for which a patient must remain in this precarious and, when consciousness returns, uncomfortable position is debatable, but it should probably be for several hours (Gabus, 1952). Although most patients either die within the first hour or recover (Hogan, 1947), a few die many hours later (Case, 1921; Le Melletier, 1945); and Abbott (1951) stated that a patient placed in the left lateral position may get a recurrence of symptoms on turning on to his back several hours after the original embolus. Case 5, in this series, showed symptoms two hours after the embolism when lowered from 24 in. $(60 \mathrm{~cm}$.) blocks to 15 in. $(37 \mathrm{~cm}$.) blocks.

The administration of oxygen, first suggested on theoretical grounds by Fine, Hermanson, and Frehling (1938), is necessary to promote the rapid absorption of intravascular nitrogen. To do this, the concentration of oxygen inhaled must be as high as possible, and a B.L.B. type mask is the most effective method. Experimentally, the administration of $100 \%$ oxygen for one to two hours alleviates and sometimes prevents the serious effects of arterial embolism in rabbits (Fine and Fischmann, 1940). As man is less sensitive to the toxic effects of oxygen than rabbits, oxygen may be given for a longer period than this, and it would appear unwise for this period to be shorter than two hours.

Aspiration of the right ventricle was first shown to lower the mortality of venous air embolism in dogs by Senn in 1885 , and he suggested that aspiration of the right auricle through a catheter passed through a vein might be a possible method of treatment in man. Joffe and Wells (1946) thought 
that aspiration of the right ventricle would be more practical and might be effective because they found only $15 \mathrm{ml}$. and $20 \mathrm{ml}$. of air in the right ventricles of two patients at necropsy. Stallworth, Martin, and Postlethwait (1950) succeeded in removing $15 \mathrm{ml}$. of air from the right ventricle by repeated aspiration of air and blood, allowing the air to separate from the blood in the syringe, and reinjecting the blood to stimulate cardiac contraction. Bingel (1923) had previously aspirated the right ventricle with recovery of the patient, but, as he only removed $3 \mathrm{ml}$. of air, it is doubtful if the aspiration really affected the result. Larson (1951) showed that in dogs aspiration of air from the right ventricle was preferable to aspiration of the right atrium because it was more effective in re-establishing the circulation and because the atrium is liable to bleed after puncture by the needle. He suggests that in man blind aspiration of the right ventricle should first be attempted by inserting a needle either below the xiphisternum or in the fifth right intercostal space near the edge of the sternum; if this fails, then aspiration under direct vision followed by cardiac massage should be performed without hesitation. Weese (1952), however, emphasizes that time is an important factor in determining the prognosis and strongly opposes exposure of the heart as the first method of aspirating the right ventricle. Although I have no experience of these techniques, it would seem advisable to be prepared to aspirate the right ventricle blindly even if the direct vision method is considered impractical.

Bichat (1832) was the first to draw attention to the fact that, in death due to air embolism, respiration stops before the heart, and this led Nancrede (1885) to suggest artificial respiration as a form of treatment. The value of artificial respiration has been confirmed by Oppenheimer and others (1953), whose experiments suggested that dogs were protected from the effects of venous air embolism when they received artificial respiration of a positive pressure type. Algenstädt and Kämpe (1952) have used artificial respiration clinically, and it is certainly indicated when respiration has stopped.

Besides the above methods of treatment for venous air embolism which all have experimental evidence to support them, injections of adrenaline or nikethamide are commonly employed. More logically vasodilators have been used, and amyl nitrite (Senn, 1885), papaverine (Joffe and Wells, 1946), and aminophylline (Algenstädt and Kämpe, 1952) have all had their supporters. To be effective these drugs must be given in intravenous or even intracardiac injection, but no time should be wasted in giving these injections until the posture of the patient has been changed, he has a good airway, and has been given oxygen.

In the refill room at Tan Tock Seng Hospital a dressing trolley is now always prepared before each refill session and contains a lumbar puncture needle and $20-\mathrm{ml}$. syringe for cardiac aspiration and syringe and needles for giving aminophylline, adrenaline, and nikethamide, together with a supply of these drugs. In order to maintain the airway of an unconscious patient, a Mason type gag, a boxwood wedge, tongue forceps, rubber airways, and sponge holders are also present. Beside the trolley are kept a pair of $24 \mathrm{in} .(60 \mathrm{~cm}$.) bed blocks and an oxygen cylinder fitted with a B.L.B. mask. With this equipment always ready, it is hoped that the mortality rate from air embolism will be lowered, and that a more careful technique will lower its incidence during pneumoperitoneum therapy.

\section{SUMmary}

Six cases of air embolism during pneumoperitoneum therapy are described and 47 cases from the literature are tabulated.

The incidence of air embolism during pneumoperitoneum therapy is estimated as 1 in every 437 inductions and 1 in every 9,000 refills. The mortality rate of these published cases of air embolism is estimated as $41.5 \%$. Although reasons are given suggesting all these figures are too high, it is estimated that $1 \%$ of patients will have an air embolism before completing three years' treatment with pneumoperitoneum.

The methods of prevention of air embolism are discussed together with the place of posture, the administration of oxygen, aspiration of the right ventricle, and artificial respiration in its treatment.

I am grateful to Dr. C. E. Smith and Dr. R. J. Grove White for permission to study patients under their care and to the latter and Dr. G. E. L. Cummings for many helpful suggestions and criticisms. I wish to thank Dr. L. S. da Silva for permission to use his necropsy report and to the Pathology Department, General Hospital, Singapore, for reproducing the radiographs.

I am indebted to the Director of Medical Services, Singapore, for permission to publish.

\section{REFERENCES}

Abbott, O. A. (1951). Personal communication to Hollander (1951). Algenstädt, H., and Kämpe, H. (1952). Tuberkulosearzt, 6, 664.

Aronovitch, M., Caswell, L. A., and Zadé, J. A. (1947). Canad. med. Ass. J., 57, 122.

Aslett, E., and Jarman, T. F. (1945). Lancet, 1, 304.

Bailey, W. H. (1948). Amer. Rev. Tuberc., 57, 621.

Banyai, A. L. (1946). Pneumoperitoneum Treatment, p. 107-9. Mosby, St. Louis.

Bariéty, M., Tacon, J. Le, and Poulet, J. (1951). Rev. Tuberc.

(Paris), 5 ser., 15, 113

Bichat, M. F. X. (1832). Quoted by Senn (1885). 
Bingel, A. (1923). Zbl. Chir., 50, 433.

Bobrowitz, I. D. (1953). Dis. Chest, $24,82$.

Bohorfoush, J. G. (1943). Amer. Rev. Tuberc., 47, 263.

Brit med. J. (1952) $2,729$.

Burgos, R. (1946). Hoja tisiol., 6, 232.

Burman, D. (1954). Med. J. Malaya, 9, 46.

Cafiero, F., and Mastropaolo, A. (1952). Minerva med. (parte sci.), $43(2), 358$.

Case, J. T. (1921). Amer. J. Roentgenol., 8, 714.

Cohen, A. C., Glinsky, G. C., Martin, G. E., and Fetterhoff, K. I. (1951). Ann intern. Med., 35, 779.

Durant, T. M. (1935) Ibid., 8, 1625

Edge, J. R. (1953). Brit. J. Tuberc., 47, 202.

Fine, J., and Fischmann, J. (1940). New Engl. J. Med., 223, 1054.

Hermanson, L., and Frehling, S. (1938). Ann. Surg., 107, 1.

Forbes, G. (1944). Brit. med. J., 2, 529.

Fourchon, J. (1950). Quoted by Cafiero and Mastropaolo (1952,

Fremmel, F. (1937). Amer. Rev. Tuberc., 36, 488.

Gabus, P. (1952). Rev. méd. Suisse rom., 72, 435.

Hamby, W. B., and Terry, R. N. (1952). Surgery, 31, 212

Hamby, W. B., and Terry, R. N. (1952). Surgery, 31, 212. 2226.

Harrell, C. L. (1940). Dis. Chest, 6, 273.

Hogan, G. F. (1947). Tuberculology, 9, 92

Hollander, A. G. (1951). J. Amer. med. Ass., 147, 568.

Joffe, H. H., and Wells, A. H. (1946). Minn. Med., 29, 1238.

Keers, R. Y (1948) Brit. J. Tuberc., 42, 58.

Lancet (1945). 1, 534.

Larson, C. P. (1951). Amer. J. clin. Path., 21, 247.

Le Bec, Y., and Bourhis, H. (1951). Presse méd., 59, 1598.

Le Melletier, J. (1945). Ibid., 53, 712.

Mellies, C. J. (1939). J. Mo. med. Ass., 36, 430.

Mitchell, R. S., Hiatt, J. S., McCain, P. P., Easom, H. F., and Thomas, C. D. (1947). Amer. Rev. Tuberc., 55, 306.
Moore, R. M., and Braselton, C. W. (1940). Ann. Surg., 112, 212. Musgrove, J. E., and MacQuigg, R. E. (1952). J. Amer. med. Ass., $150,28$.

Nancrede, C. B. (1885). Trans, Amer, surg. Ass., 3, 307.

Negro, J. C. (1939). Rev. Tuberc. Urug., 8, 222.

Oppenheimer, M. J., Durant, T. M., and Lynch, P. (1953). Amer. J. med. Sci., $225,362$.

Orlowski, E. H. (1951). Klin. Wschr., 29, 269.

Puchowski, B. (1952). Gruzlica, 20, 69.

Ribotto, L. (1951). Personal communication to Cafiero and Mastropaolo (1952).

Rilance, A. B., and Warring, F. C. (1941). Amer. Rev. Tuberc., 44, 323.

Roche, G., and Giron, J. (1944). Rev. Tuberc. (Paris), 5 ser.. 9,

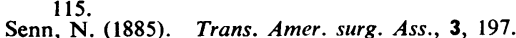

Shubin, H. (1952). Tuberculology, 12, 224.

Simmonds, F. A. H. (1946). Lancet, 1, 530.

Sita-Lumsden, E. G., and Elphinstone, R. H. (1950). Brit. med. J., $1,166$.

Stallworth, J. M., Martin, J. B., and Postlethwait, R. W. (1950). J. Amer. med. Ass., 143, 1250 .

Stein, H. F. (1951). Amer. Rev. Tuberc., 64, 645

Stokes, J. B. (1938). Illinois med. J., 73, 137.

Taraglio, M. (1947). Gazz. med. ital., 106, 33

Taylor, J. D. (1952). Brit. med. J., 1, 890.

Trimble, H. G., Eaton, J. L., Crenshaw, G. L., and Gourley, I. (1948). Amer. Rev. Tuberc., 57, 433.

Warring, F. C., and Thomas, R. M. (1940). Ibid., 42, 682.

Weiss, R. (1951). Fortschr. Röntgenstr., 75, 79.

Weese, K. (1952). Chirurg., 23, 515.

Wolffe, J. B., and Robertson, H. F. (1935). Ann. intern. Med., 9, 162. 